- One of the most challenging aspects of restorative dentistry is colour assessment and its reproduction.

- An increasing number of computer-based instruments for shade selection have entered the market.

- Manufacturers claim that these instruments remove the subjectivity associated with visual shade mapping and facilitate more consistent and accurate measurements.

- This clinical investigation assessed the ability of three tooth colour measuring devices to repeat their own results under standardised clinical conditions.

- Spectroshade Micro ${ }^{\mathrm{TM}}$ was the most repeatable device tested.

\title{
A clinical evaluation of the individual repeatability of three commercially available colour measuring devices
}

\author{
R. Khurana, ${ }^{1}$ C. J. Tredwin, ${ }^{2}$ M. Weisbloom ${ }^{3}$ and D. R. Moles ${ }^{4}$
}

Objective The objective of this study was to undertake a clinical evaluation of the individual repeatability of three colour measuring devices.

Design Clinical study.

Setting Eastman Dental Hospital.

Methods Under standardised clinical conditions, one trained operator using three colour measuring devices (Vita Easyshade, X-Rite ShadeVision and Spectroshade Micro) recorded three shade measurements (cervical, body and incisal) for each of the upper maxillary anterior teeth in 20 participants. This sequence of measurements was repeated for each of the shade machines. The output recorded from each sequence included Vita classic shades and CIE Lab co-ordinates. Ethical approval was obtained from the joint University College London and University College London Hospitals.

Results Spectroshade Micro had good agreement Cohen Kappa score (0.80) for repeatability of Vita shades and also had $82.7 \%$ proportion of complete agreement for Vita shades. The proportion of complete agreement for Vita shades for the Easyshade and X-Rite ShadeVision machine were $50 \%$ and $59 \%$ respectively. For CIE Lab co-ordinates the Spectroshade Micro provided the narrowest range of 'Bland and Altman' agreement limits for all the co-ordinates recorded.

Conclusion The Spectroshade Micro machine provided the most repeatable measurements. Narrower limits of agreement indicate greater consistency compared to Easyshade and X-Rite ShadeVision.

${ }^{1}$ Graduate Student, Unit of Conservative Dentistry, ${ }^{2 *}$ Clinical Lecturer/Honorary Specialist Registrar in Restorative Dentistry, ${ }^{3}$ Senior Chief Instructor Technician, ${ }^{4}$ Senior Clinical Lecturer in Health Sciences Research, UCL Eastman Dental Institute, 256

Gray's Inn Road, London, WC1X 8LD

*Correspondence to: Dr Christopher J. Tredwin

Email:c.tredwin@eastman.ucl.ac.uk

\section{Refereed Paper}

Accepted 24 April 2007

DOI: $10.1038 /$ bdj.2007.1108

${ }^{\circledR}$ British Dental Journal 2007; 203: 675-680

\section{INTRODUCTION}

The demand for attractive restorations challenges the restorative dentist to produce prostheses that duplicate the form, function and appearance of the natural dentition. The appearance of any restoration depends on outline form, surface form, translucency and colour. ${ }^{1}$ Aesthetically superior restorations are now possible as a result of improvements in dental materials and manufacturing techniques. However, one of the most challenging aspects of restorative dentistry is colour assessment and its reproduction.

The physical production of colour requires three elements: a light source, an object and a detector. ${ }^{2}$ The detector can be the eye and brain of the observer, or a sensor connected to a computer. Controlling the colour of dental restorations is difficult primarily because the task is completed visually. The process is affected by many factors, such as individual differences in understanding and perceiving colour, ${ }^{3-5}$ experience of the operator, ${ }^{2,5}$ lighting, ${ }^{2,3,6}$ and surrounding gingival colour. ${ }^{6}$ Moreover, visual assessment is often communicated to a laboratory technician through the use of inadequate shade guides ${ }^{7,8}$ and shade guides by the manufacturer may differ slightly. ${ }^{1,7,8}$

Instruments such as spectrophotometers and colorimeters have been used in industrial and research settings for the evaluation and specifications of colour. Spectrophotometers measure the reflectance or transmittance factors of an object one wavelength at a time. They have been used to measure the spectral curves of porcelains and extracted teeth. ${ }^{1,9-12}$ However, widespread use of spectrophotometers in dental research and clinical settings has been hindered by the fact that the equipment is complex and expensive and, more importantly, that it is difficult to measure the colour of teeth in vivo with these machines. Since the end of the 1990s, an increasing number of computer-based instruments for shade selection have entered the market (Table 1). Manufacturers claim that these instruments remove the subjectivity associated with visual shade mapping and facilitate more consistent and accurate measurements. 
Table 1 The range of computer-based instruments for shade selection on the market

\begin{tabular}{|c|c|c|c|c|}
\hline Unit & Manufacturer & Type of unit & $\begin{array}{l}\text { Type of } \\
\text { measurement }\end{array}$ & $\begin{array}{l}\text { Launch } \\
\text { date }\end{array}$ \\
\hline $\begin{array}{l}\text { Shade- } \\
\text { Eye-NCC }\end{array}$ & $\begin{array}{l}\text { Shofu Dental Inc., } \\
\text { San Marcos, USA }\end{array}$ & Colorimeter & Spot on tooth & 1997 \\
\hline $\begin{array}{l}\text { Dental Color } \\
\text { Analyzer }\end{array}$ & $\begin{array}{l}\text { Wolf Industries Inc., } \\
\text { Vancouver, Canada }\end{array}$ & Spectrometer & Spot on tooth & 1998 \\
\hline Shadescan & $\begin{array}{l}\text { Cynovad, Montreal, } \\
\text { Canada }\end{array}$ & $\begin{array}{l}\text { RGB digital } \\
\text { camera }\end{array}$ & $\begin{array}{l}\text { Complete } \\
\text { tooth }\end{array}$ & 2000 \\
\hline $\begin{array}{l}\text { Digital Shade } \\
\text { Guide DSG4 }\end{array}$ & $\begin{array}{l}\text { A Reith, Schorndorf, } \\
\text { Germany }\end{array}$ & Colorimeter & Spot on tooth & 2001 \\
\hline Ikam & $\begin{array}{l}\text { Metalor Technolo- } \\
\text { gies Dental Division, } \\
\text { North Attleboro, USA }\end{array}$ & $\begin{array}{l}\text { RGB digital } \\
\text { camera }\end{array}$ & $\begin{array}{l}\text { Complete } \\
\text { tooth }\end{array}$ & 2001 \\
\hline ShadeVision & $\begin{array}{l}\text { X-Rite Inc., } \\
\text { Grandville, USA }\end{array}$ & Colorimeter & $\begin{array}{l}\text { Complete } \\
\text { tooth }\end{array}$ & 2001 \\
\hline Spectroshade & $\begin{array}{l}\text { MHT Optic Research } \\
\text { AG, Niederhasli, } \\
\text { Switzerland }\end{array}$ & Spectrometer & $\begin{array}{l}\text { Complete } \\
\text { tooth }\end{array}$ & 2001 \\
\hline $\begin{array}{l}\text { Vita } \\
\text { Easyshade }\end{array}$ & Vident, Brea, USA & Spectrometer & Spot on tooth & 2002 \\
\hline Identacolor || & Idental Ltd. & Spectrometer & Spot on tooth & 2003 \\
\hline
\end{tabular}

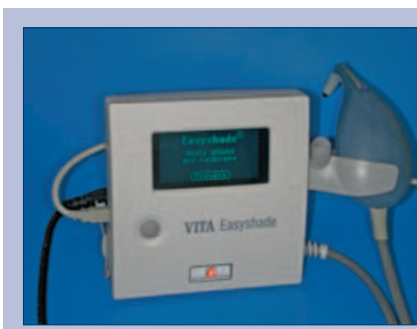

Fig. 1 The Vita Easyshade

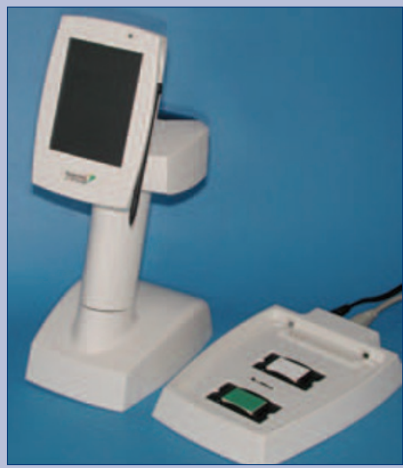

Fig. 2 The Spectroshade Micro

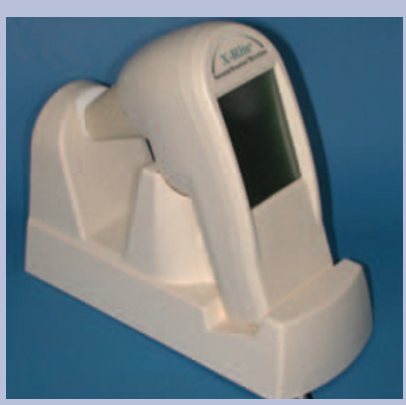

Fig. 3 The X-Rite ShadeVision

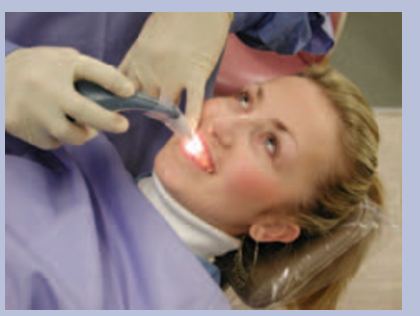

Fig. 4 The Vita Easyshade in clinical use

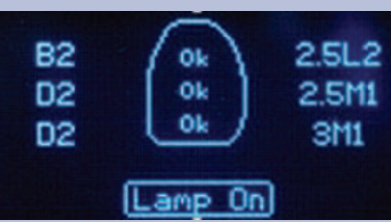

Fig. 5 Standard shade display from the Vita Easyshade

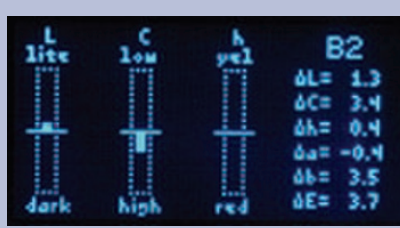

Fig. 6 Extended mode display from the Vita Easyshade
Studies assessing colour measuring devices (CMDs) have provided mixed results, rendering the clinical usefulness of these instruments unclear. ${ }^{11,13-21}$ The purpose of this study was to measure the repeatability of three commercially available CMDs under clinical conditions using one trained operator.

\section{MATERIALS AND METHODS}

Three commercially available CMDs were used in this study. These machines were the Vita Easyshade spectrophotometer (Version 1IO - Panadent limited, UK) (Fig. 1), the Spectroshade Micro spectrophotometer (Version 2.4 - Medical High Technologies, Italy) (Fig. 2) and the ShadeVision system colorimeter-Xrite (Version 3.01 - ShadeVision, USA) (Fig. 3).

Ethical approval was obtained from the joint University College London (UCL) and University College London Hospitals (UCLH) ethics committee. Twenty healthy patient volunteers with an unrestored intact maxillary dentition were recruited for the study.

One operator who had received training with the three colour measuring devices recorded all measurements. The colour measurements were made in the dental clinic which has plentiful natural daylight. A thermometer was used to monitor the room temperature, which was kept at $26^{\circ} \mathrm{C}$. All measurements were made between $10 \mathrm{am}$ to $2 \mathrm{pm}$ on five separate occasions.

The patients were instructed to lean their heads against the headrest of the treatment chair during the measurement and to keep their mouth slightly opened. The machines were used and calibrated according to the manufacturer's recommendations. The maxillary canines and incisors (six teeth) had their shades recorded at three sites - cervical, middle and incisal. During measurements the participants were instructed to keep their tongue in a relaxed position away from the maxillary teeth to prevent this affecting tooth translucency and causing a false measurement. The process was repeated to acquire a second sequence of shades using each of the machines. The patient was provided with a glass of water to be sipped after each sequence to prevent dehydration of the teeth. Gauze squares were used to remove any excessive surface moisture prior to shade taking. Vita shades and CIE Lab data were recorded for each measurement.

\section{Measurements with Vita Easyshade}

An infection control shield was placed over the recording head of the Easyshade hand piece and the machine was calibrated. Subsequently the 'Tooth areas' on the screen menu was selected allowing measurement of the cervical, middle and incisal areas of the tooth. The probe tip was positioned at $90^{\circ}$ to the surface of the tooth (Fig. 4) and the shade recorded. Figure 5 shows the standard shade display and Figure 6, the extended shade display obtained with the Vita Easyshade.

\section{Measurements with Spectroshade}

An infection control mouthpiece and adhesive pad were positioned on the optic handpiece following calibration. After the measure button was depressed, an intense band of coloured light was emitted and the mouthpiece was carefully positioned over the tooth required (Fig. 7). The screen allows the examiner to 'frame' the tooth and when the tooth was in the desired position it was verified by a horizontal green line (indicating correct geometry), and the shade recorded. After a sequence (six teeth) of 


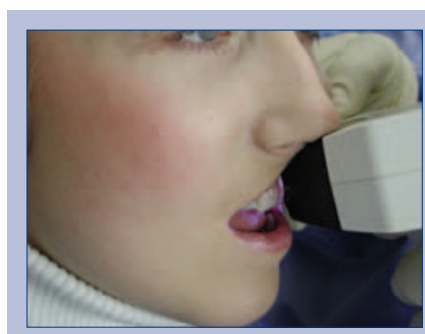

Fig. 7 The Spectroshade Micro in clinical use

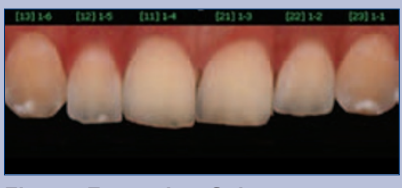

Fig. 8 Example of the output display for the Spectroshade Micro

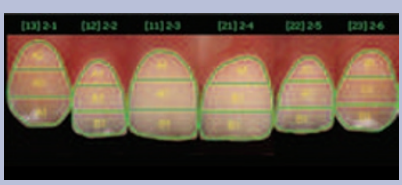

Fig. 9 Use of the Spectroshade Micro software to outline the teeth and select Vita shade

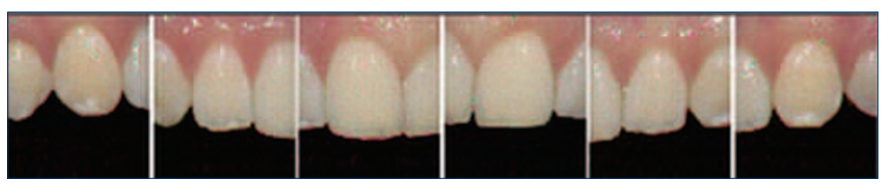

Fig. 12 Tooth sequence display from the X-Rite ShadeVision

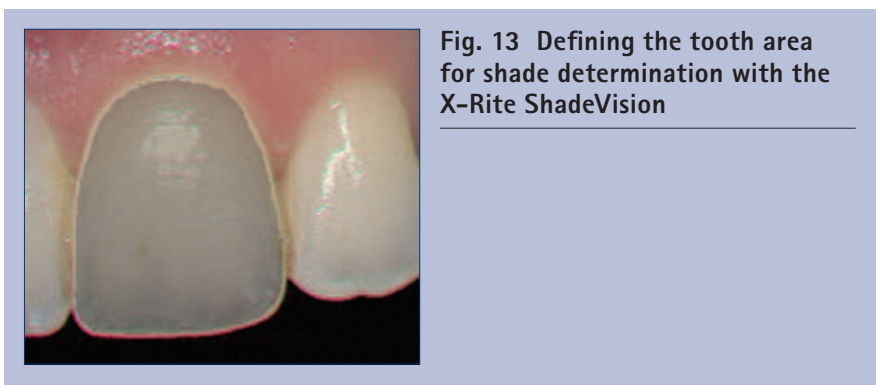

measurements was completed, the unit was returned to the docking cradle for downloading of images. An example of the display that was obtained for six teeth is shown in Figure 8. By selecting the 'parts' button, the software automatically outlined the teeth and Vita shades were selected (Fig. 9). The CIE Lab co-ordinates were also recorded for each site of each tooth (Fig. 10).

\section{Measurement with X-Rite ShadeVision}

The measure patient option was selected from the X-Rite ShadeVision software window, the software then automatically calibrated the handpiece. Subsequently the tooth to be measured was selected on the handpiece screen and the measure button was pressed (Fig. 11), the tooth was illuminated and a countdown began (approximately $5 \mathrm{~s}$ ). A thumb and forefinger were used as a fulcrum to aid in aligning the tip against the tooth surface. The ShadeVision tip was rested against the tooth and

\begin{tabular}{|c|c|}
\hline Shade machine & $\begin{array}{l}\text { Percentage proportion } \\
\text { of complete agreement }\end{array}$ \\
\hline Vita Easyshade & 50 \\
\hline Spectroshade Micro & 82.7 \\
\hline X-Rite ShadeVision & 59.7 \\
\hline
\end{tabular}

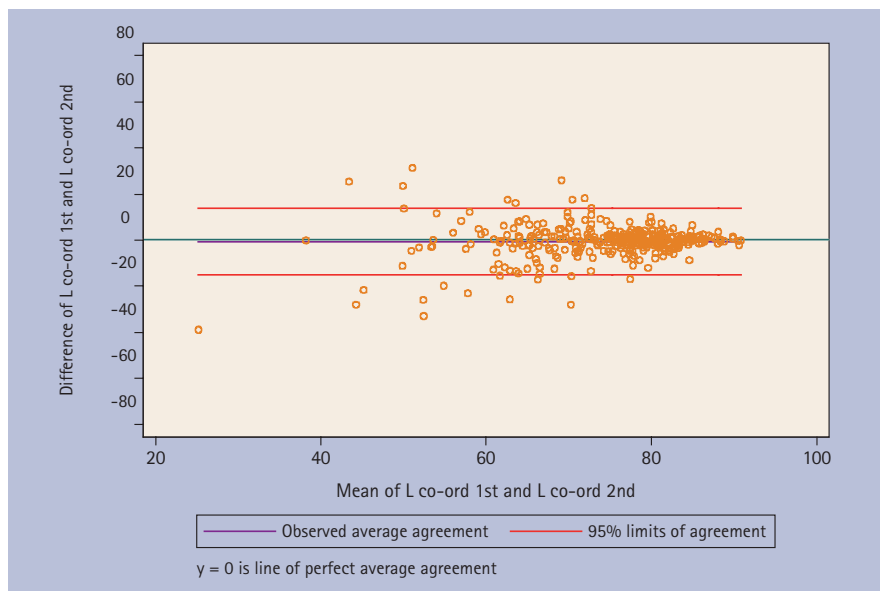

Fig. 14 Bland and Altman scatter plot to show repeatability of $\mathrm{L}$ co-ordinates for the Vita Easyshade machine

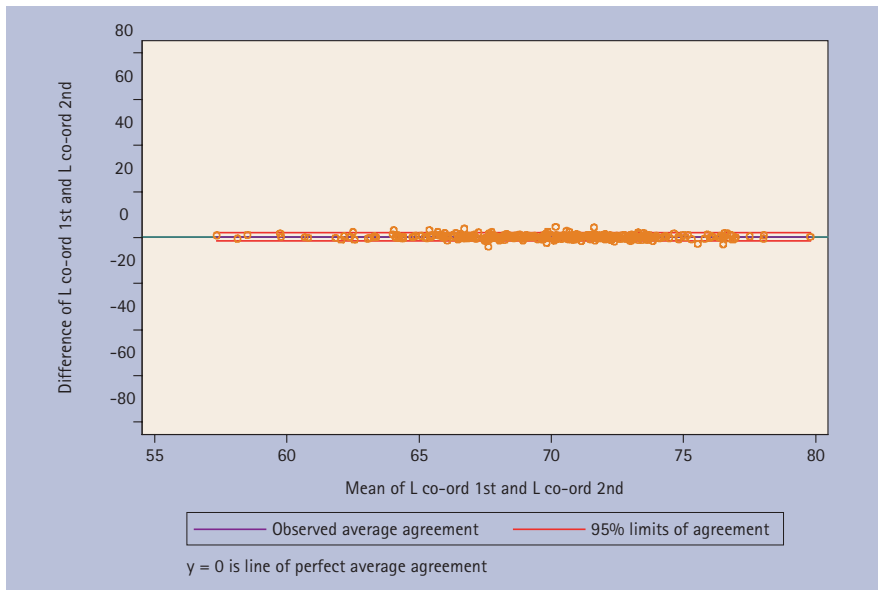

Fig. 15 Bland and Altman scatter plot to show repeatability of $\mathrm{L}$ co-ordinates for the Spectroshade Micro machine

gingival area, ensuring it was flush and square with the tooth surface. The instrument was positioned such that the highlights showed in the medial cervical third of the tooth. The participants tooth sequence was displayed (Fig. 12) and using the wizard tool, the active tooth area was defined (Fig. 13).

Repeatability for categorical data (Vita shades) obtained from the main study were analysed using the Kappa statistic. Following an initial pilot study it was found that if the machines did not use the same range of Vita shades, then a symmetrical two-way table could not be formed and a Kappa score was unable to be computed. Therefore the proportions of agreements were calculated instead. Continuous (numerical) data obtained from the study were analysed using the Bland and Altman approach. ${ }^{22}$ This entailed plotting the difference between the pairs of measurements against the means of the pairs and calculating the 'limits of agreement'. 


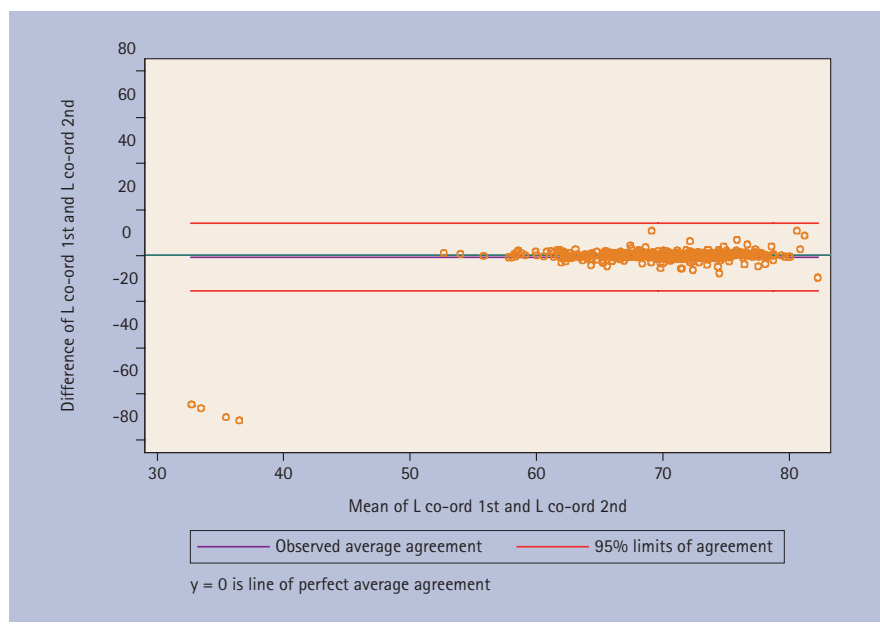

Fig. 16 Bland and Altman scatter plot to show repeatability of $\mathrm{L}$ co-ordinates for the $\mathrm{X}$-Rite ShadeVision machine

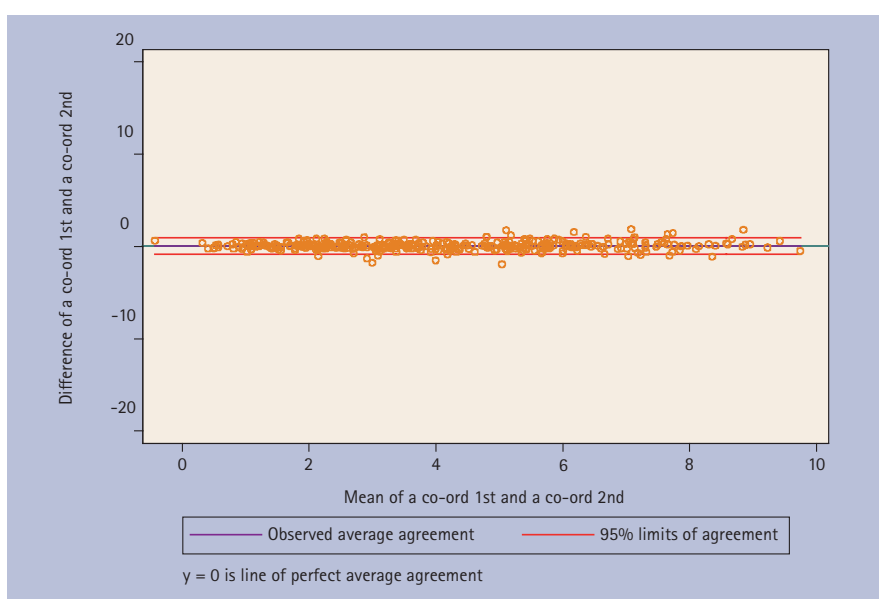

Fig. 18 Bland and Altman scatter plot to show repeatability of a co-ordinates for the Spectroshade Micro machine

\section{RESULTS}

The Spectroshade Micro revealed a Kappa score of 0.8 for the repeatability of the Vita shades obtained. Kappa statistics could not be produced for the Vita Easyshade or the X-rite ShadeVision, as a symmetrical two-way table in which the values of the first variable match the values of the second variable was not produced. The Vita Easyshade machine produced D4 shades in one sequence and not the other. The X-Rite ShadeVision machine produced C2 and D4 shades in one sequence and not the other.

Table 2 shows the proportion of complete agreements of Vita shades obtained for each of the three machines.

Figures 14 to 22 show the Bland and Altman scatter plots obtained for the L, a and b co-ordinates for the Vita Easyshade, Spectroshade and ShadeVision colour measuring devices.

\section{DISCUSSION}

Due to the nature of colour science, the true colour of the patients' teeth used in this study is unknown; therefore, the only standard by which the machines could be judged is by their ability to repeat their own results. Neither Easyshade nor X-Rite ShadeVision were able to produce a symmetrical two-way table and hence Kappa scores could not be computed. On this basis alone they were not as repeatable for Vita shades as the Spectroshade Micro machine. The Spectroshade Micro machine provided a Kappa value of

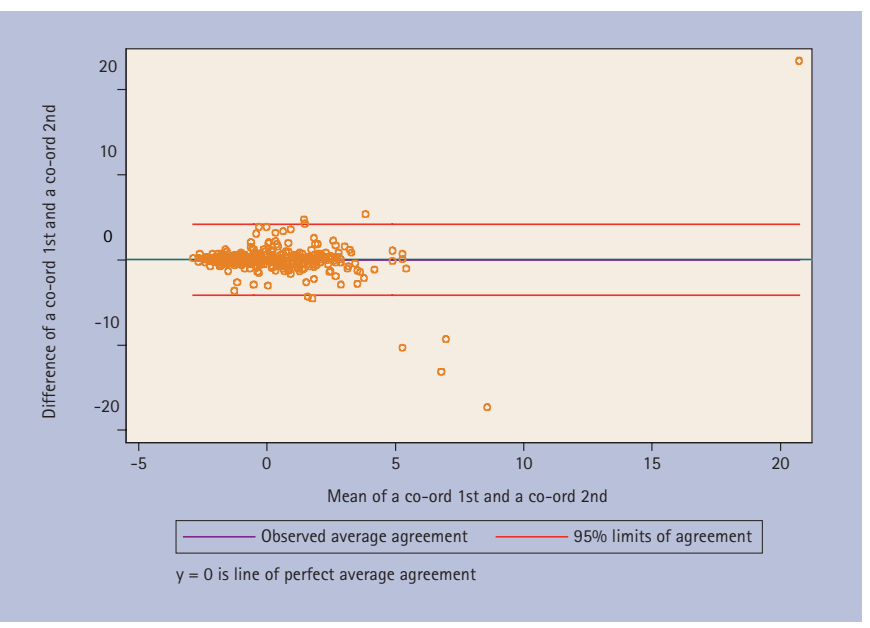

Fig. 17 Bland and Altman scatter plot to show repeatability of a co-ordinates for the Vita Easyshade machine

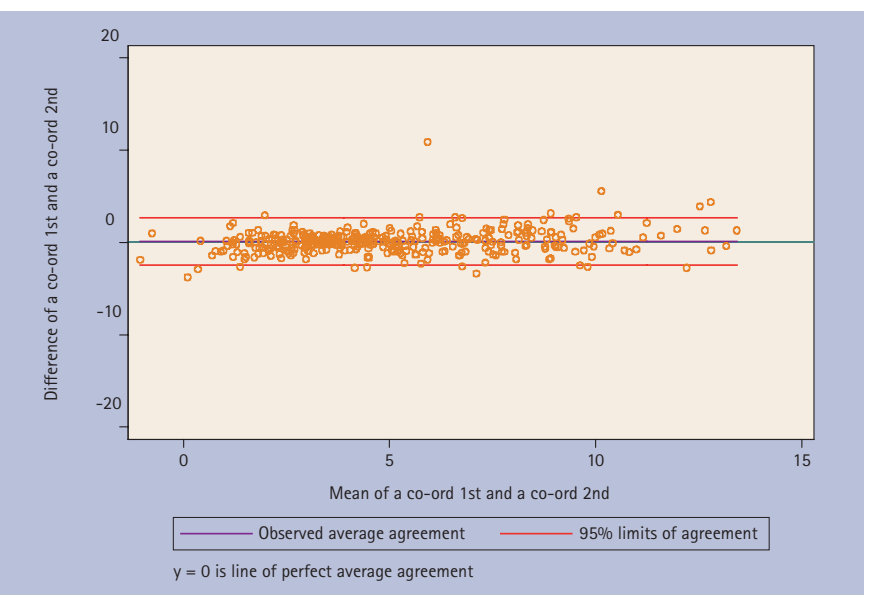

Fig. 19 Bland and Altman scatter plot to show repeatability of a co-ordinates for the $\mathrm{X}$-Rite ShadeVision machine

0.80 , which can be interpreted as good agreement between the first and second sequence of measurements. This machine also provided the highest proportion of complete agreement, with 82.7\%.Vita Easyshade and X-Rite ShadeVision scored 50\% and $59.7 \%$ respectively. It should, however, be noted that the proportion of complete agreement calculation does not take into account the probability of the agreement occurring by chance.

The L (brightness) co-ordinates are measured on a scale from 0 (black) to 100 (white). The brightness parameter is probably the most significant because the human eye can perceive differences in the lightness or darkness of shades more easily than it can detect variations in hue. On 95\% of occasions the Vita Easyshade machine gave results that were within approximately 15 units of each other. Spectroshade Micro results were in a range of less than two units of each other. ShadeVision provided a similar range to Vita Easyshade. This narrower grouping with the Spectroshade Micro measurements indicates greater repeatability compared to the other machines.

The a value is a measure of redness $(+60)$ or greenness $(-60)$. On 95\% of occasions the Vita Easyshade gave results within approximately four units of each other. X-Rite ShadeVision gave results within just over two units of each other and Spectroshade gave results that were within less than one unit of each other. Again this narrower grouping indicated superior repeatability with the Spectroshade Micro machine. 


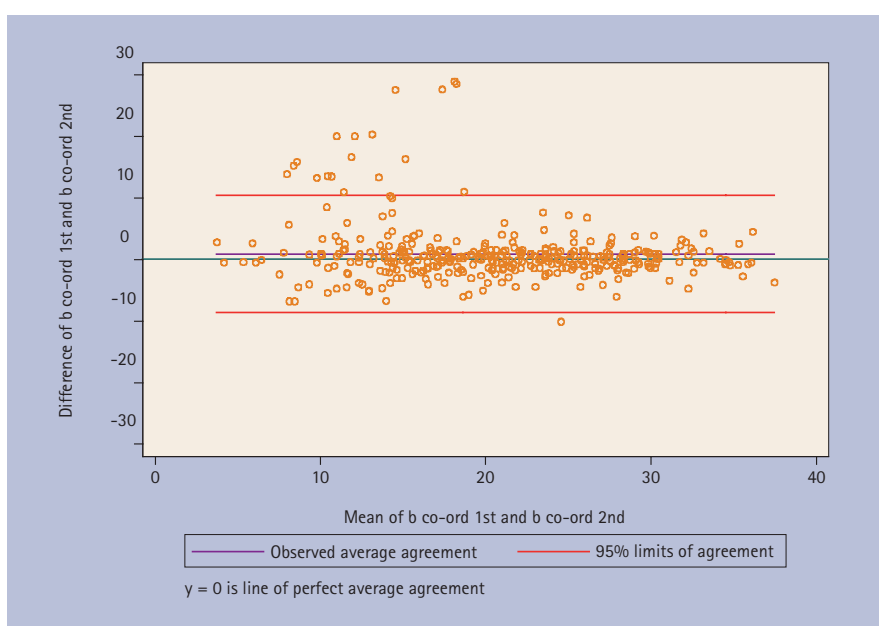

Fig. 20 Bland and Altman scatter plot to show repeatability of b co-ordinates for the Vita Easyshade machine

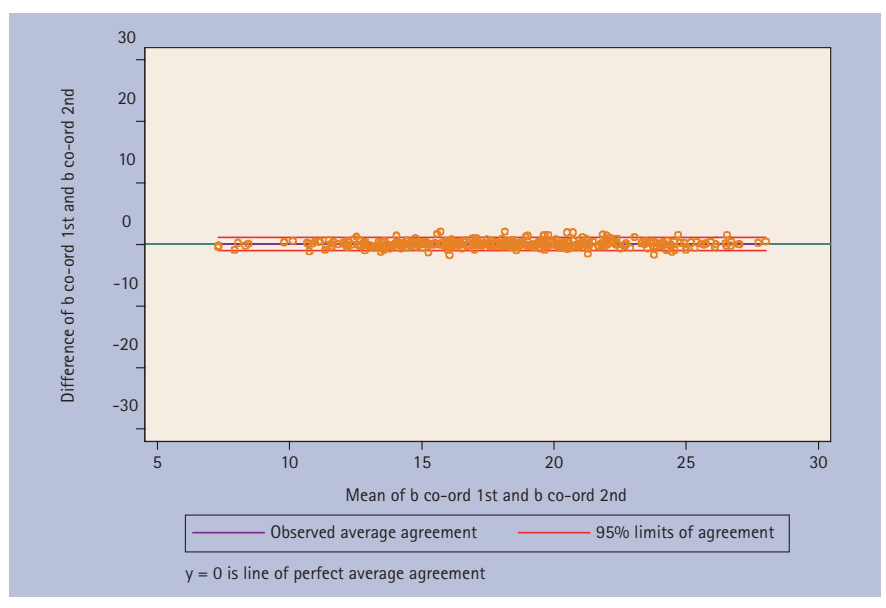

Fig. 21 Bland and Altman scatter plot to show repeatability of b co-ordinates for the Spectroshade Micro machine

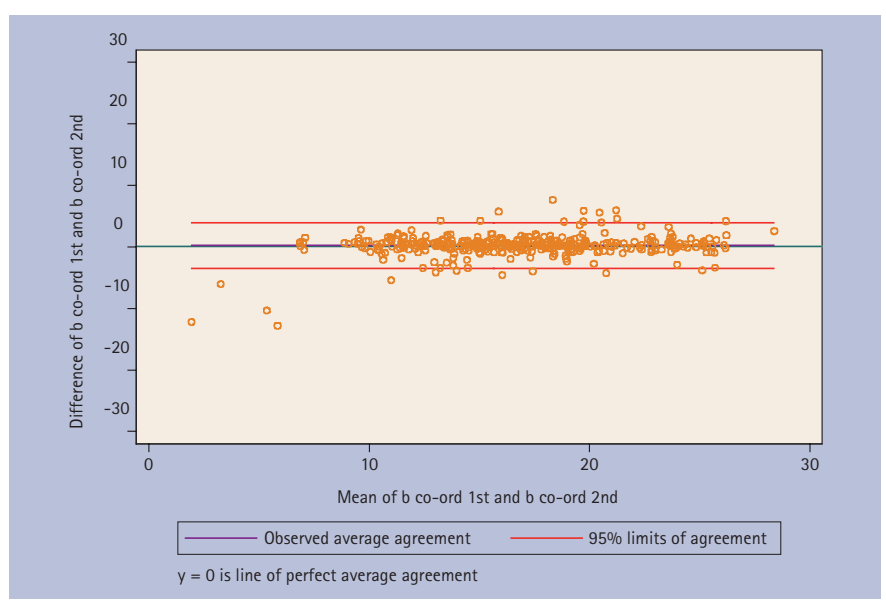

Fig. 22 Bland and Altman scatter plot to show repeatability of b co-ordinates for the X-Rite ShadeVision machine

The $b$ value is a measure of yellowness $(+60)$ or blueness $(-60)$. On 95\% of occasions the Spectroshade Micro machine gave results that were within one unit of each other. The limits of agreement for ShadeVision and Easyshade were much larger, from 3.848 to -5.544 and -8.722 to 10.418 respectively. The narrower grouping of results again illustrated greater repeatability by the Spectroshade machine.

It can be seen that universally, the Spectroshade Micro machine provided the most repeatable measurements, with narrower limits of agreement indicating greater consistency compared to the other two machines used.

Dental measurement devices can be broadly categorised as either a spot measurement (SM) or a complete tooth measurement (CTM) device. The Vita Easyshade is an example of an SM device, while the X-Rite ShadeVision and Spectroshade Micro are examples of CTM devices. SM devices measure a small area on the tooth determined by the diameter of the optical device aperture (usually $3 \mathrm{~mm}^{2}$ ) and consequently, several reference measurements may be required. It has been stated that the data collected for SM machines may not be entirely accurate because of the non-homogenous shade structure of the tooth, the increased potential for tooth dehydration and errors in image capture. ${ }^{23}$ Conversely, CTM devices present a topographical colour map of the whole tooth in one image and it has been suggested that this provides more consistent and reproducible information about the tooth structure. ${ }^{23}$

A colorimeter is an instrument used for measuring CIE tristimulus values for a stimulus. The X-Rite ShadeVision is an example of a colorimeter. Colorimeters generally use three or four silicon photodiodes that have spectral correction filters that closely simulate the standard observer functions. These filters act as analogue function generators that limit the spectral characteristics of the light that strikes the detector (filter) surface.

Spectrophotometers measure and record the amount of visible radiant energy reflected or transmitted by an object one wavelength at a time for each value, chroma and hue present in the entire visible spectrum. ${ }^{23}$ The Vita Easyshade and Spectroshade Micro are examples of spectrophotometers. The main components of all spectrophotometers are a source of optical radiation, an optical system for defining the geometric conditions of measurement, some means of dispersing light, a sample (eg a translucent tooth), a detector and a signal processing system that converts light into signals suitable for analysis. Such devices give control over external light conditions and the photo-optical measurement allows quantification of colour using CIE Lab co-ordinates. Following measurement, a spectral reflectance curve is generated.

Characterising and reproducing colour remains one of the most challenging aspects of dentistry. The arrival of colour measuring instruments to the market is a welcome step; this study demonstrated that the Spectroshade Micro machine was the most repeatable machine tested. However, repeatability is not an indicator of shade measurement accuracy and therefore there is no certainty that instrumental measurement will correlate to visual judgements. Hence, within the limitations of this study, patient perceptibility and acceptance cannot be predicted and further research is required.

\section{CONCLUSIONS}

Within the limitations of this clinical study the following conclusion may be drawn:

Under standardised conditions, Spectroshade Micro - a complete tooth mapping spectrophotometer - was the most repeatable device in recording tooth shades clinically. It had a good proportion of complete agreement, which was higher than both a colorimeter (X-Rite ShadeVision) and a spot measurement spectrophotometer (Vita Easyshade). 
1. Seghi R R, Johnston W M, O'Brien W J. Spectrophotometric analysis of colour differences between porcelain systems. J Prosthet Dent 1986; 56: 35-40.

2. Berns R S, Bilmeyer FW Jr, Saltzman M. Bilmeyer and Saltzman's principles of colour technology. 3rd ed. pp 31-105. New York: John Wiley and Sons, 2000.

3. Hunter R S. The measurement of appearance. 2nd ed. New York: John Wiley, 1987.

4. O'Brien W J. A new, small-color-difference equation for dental shades. J Dent Res 1990; 69: 1762-1764.

5. Culpepper W D. A comparative study of shade matching procedures. J Prosthet Dent 1970; 24: 166-173.

6. Yamamoto M. Metal-ceramics. Principles and methods of Makoto Yamamoto. Chicago: Quintessence, 1985.

7. Sproull R C. Colour matching in dentistry. Part II: practical applications for the organization of colour. J Prosthet Dent 1973; 29: 556-566.

8. Sproull R C. Colour matching in dentistry. Part III: colour control. J Prosthet Dent 1973: 31: 146-154.

9. Kato T, Kuwata M, Tamura K, Yamamoto M. The current state of porcelain shades: a discussion. Quintessence Dent Technol 1984; 8: 559-571.

10. Ishikawa-Nagai S, Sato R R, Shiraishi A, Ishibashi K. Using a computer colormatching system in color reproduction of porcelain restorations. Part 3: a newly developed spectrophotometer designed for clinical application. Int J Prosthodont 1994; 7: 50-55.

11. Macentee $M$, Lakowski R. Instrumental colour measurement of vital and extracted human teeth. J Oral Rehabil 1981; 8: 203-208.

12. O'Brien W J, Johnston W M, Fanian F. Double layer colour effects in porcelain systems. J Dent Res 1985; 64: 940-943.
13. Van der Burgt T P, Bosch J J, Borsboom P C, Kortsmit W J. A comparison of new and conventional methods for quantification of tooth colour. J Prosthet Dent 1990; 63: 155-162

14. Seghi R R. Effects of instrument-measuring geometry on colorimetric assessments of dental porcelains. J Dent Res 1990; 69: 1180-1183.

15. Okubo S R, Kanawati A, Richards M W, Childress S. Evaluation of visual and instrumental shade matching. J Prosthet Dent 1998; 80: 642-648.

16. Chu S J, Tarnow D P. Digital shade analysis and verification: a case report and discussion. Pract Proced Aesthet Dent 2001; 13: 129-136.

17. Chu S J. The science of color and shade selection in aesthetic dentistry. Dent Today 2002; 21(9): 86-89.

18. Paul S J, Peter A, Rodoni L, Pietrobon N. Conventional visual vs spectrophotometric shade taking for porcelain-fused-to-metal crowns: a clinical comparison. Int J Periodontics Restorative Dent 2004; 24: 222-231.

19. Dagg H, O'Connell B, Claffey N, Byrne D, Gorman C. The influence of some different factors on the accuracy of shade selection. J Oral Rehabil 2004; 31 : 900-904.

20. Jarad F D, Russell M D, Moss B W. The use of digital imaging for colour matching and communication in restorative dentistry. Br Dent J 2005; 199: 43-49.

21. Hugo B, Witzel T, Klaiber B. Comparison of in vivo and computer-aided tooth shade determination. Clin Oral Investig 2005; 9: 244-250.

22. Bland J M, Altman D G. Statistical methods for assessing agreement between two methods of clinical measurement. Lancet 1986; 8: 307-310.

23. Chu S J, Devigus A, Mieleszko A. Fundamentals of color. Chicago: Quintessence, 2004. 